[3] Alcohol consumption should be avoided, as it increases the likelihood of adverse effects from the treatment.

[4] Common side effects include nausea or gastrointestinal distress, loss of appetite, headache and fatigue after taking each weekly dose of the drug.

If this happens, you can take the daily dose in two doses, avoid taking large amounts and drink plenty of water on the day of administration. If in spite of everything, they do not disappear, you should consult the Rheumatology Unit.

[5] It is recommended to use sun protection.

[6] Pregnancy and breastfeeding should be avoided while taking MTX. In case of pregnancy desire, you should consult the Rheumatology service in order to schedule a withdrawal of the treatment. In case of unplanned pregnancy, stop treatment and contact the Rheumatology Unit immediately.

[7] The annual flu vaccine is recommended. Consultation with the Rheumatology Unit is recommended for additional vaccines.

[8] The benefits of MTX take several weeks to appear, so you should not modify or interrupt the treatment on your own.

[9] Throughout the treatment, regular tests will be performed to monitor the safety and effectiveness of the drug.

[10] In case of doubts, and in case of infection, surgical intervention, oncological pathology or pregnancy, contact the Rheumatology Unit.

Conclusion: This leaflet is intended to resolve common doubts of patients receiving treatment with MTX, and thus contribute to improve the therapeutic adherence and avoid errors in the drug taking.

Disclosure of Interests: None declared

DOI: 10.1136/annrheumdis-2020-eular.3330

\section{FRI0615-HPR CAN DEDICATED COMMUNITY HEALTH HUBS IMPROVE PHYSICAL ACTIVITY IN A MULTI-ETHNIC RHEUMATOLOGY PRACTICE?}

J. Begum ${ }^{1}$, M. K. Nisar ${ }^{1} .^{1}$ Luton and Dunstable University Hospital, Luton, United Kingdom

Background: Self care is an important management strategy for people with inflammatory arthritis (IA). Focused education should enable people to manage their life with IA and optimise their health and well-being. Several studies have shown positive effects of dedicated health programs on a range of patient reported outcomes such as self-efficacy, pain, fatigue, quality of life and overall well-being. However these benefits are only achievable and long lasting if people are provided with professional support to stay motivated and make appropriate adjustments to obtain better health

Objectives: The objective of our intervention was to assess the outcomes of a dedicated health education program delivered in a diverse community setting represented by minorities with poor educational and socio-economic background.

Methods: We partnered with our local authority to establish a dedicated rheumatology community health hub for our patients with long term rheumatic conditions. Both clinical and paramedical staff in rheumatology clinics advertised the service and those who consented were referred. They were offered a 1:1 assessment with a health and well-being practitioner who would refer onwards based on the needs of the patient. In this pilot study we analysed the outcomes achieved at one year. Results: 187 patients were referred to the service. 158 had IA and 29 had osteoporosis. 57 (30\%) were White, 86 (46\%) Asian, 26 (14\%) Afro-Caribbean and $18(10 \%)$ of other ethnicity. Mean age was 64 years (range 36-95). Interventions included weight management $(10 \%)$, general health check $(4 \%)$, dedicated exercise program (30\%), physical activities (46\%) and talking therapies $(8 \%)$ and smoking cessation (2\%). $100 \%$ responded to the contact and signed up for the intervention. $80 \%$ completed a minimum of 12 week intervention. $89 \%$ continued to attend physical activity at least once a week long term. Only five service users dropped out for varying reasons.

Conclusion: Physical activity programs can be successful in a diverse community setting with patients from low socio-economic and educational classes. There is a need to engage these patients and offer professional support which can produce carry-over effects on physical outcomes and enhance patients' long-term adherence to such programmes. Our study demonstrates that patient activation for self management and improved physical activity can be attained irrespective of patients' backgrounds.

Disclosure of Interests: Julie Begum: None declared, Muhammad Khurram Nisar Grant/research support from: Muhammad Nisar undertakes clinical trials and received support (including attendance at conferences, speaker fees and honoraria) from Roche, Chugai, MSD, Abbvie, Pfizer, BMS, Celgene, Novartis and UCB, Consultant of: Muhammad Nisar undertakes clinical trials and received support (including attendance at conferences, speaker fees and honoraria) from Roche, Chugai, MSD, Abbvie, Pfizer, BMS, Celgene, Novartis and UCB, Speakers bureau: Muhammad Nisar undertakes clinical trials and received support (including attendance at conferences, speaker fees and honoraria) from Roche, Chugai, MSD, Abbvie, Pfizer, BMS, Celgene, Novartis and UCB DOI: 10.1136/annrheumdis-2020-eular.1988

\section{FRI0616-HPR SOCIAL SUPPORT WORKS BETTER IN RHEUMATOID} ARTHRITIS THAN FIBROMYALGIA

H. Kesmen ${ }^{1}$, A. K. Cengiz ${ }^{2}$, A. Bilgici ${ }^{2}$, G. Alayli ${ }^{2}$, D. Durmus ${ }^{2} .{ }^{1}$ Samsun Physical Medicine and Rehabilitation Hospital, Physical Medicine and Rehabilitation, Samsun, Turkey; ${ }^{2} 19$ Mayis University Faculty of Medicine, Physical Medicine and Rehabilitation, Samsun, Turkey

Background: Social support is defined as a helpful resource that can meet an individual's urgent needs and is provided by a network of others, such as family members, friends, colleagues and other communities. Perceived social support (PSS) is the subjective support that individuals may experience, emphasizing the individual's self-understanding, experience and feelings of social support from different sources. Social support directly exerts beneficial effects on the health-related quality of life in rheumatoid arthritis and fibromyalgia patients.

Objectives: The aim of this study is to compare the effect of perceived social support on quality of life of rheumatoid arthritis and fibromyalgia patients. The effect of social support from family, friends and significant others are examined separately. Methods: Fifty-eight patients with rheumatoid arthritis, fifty patients with fibromyalgia and fifty healhy controls were enrolled in the study. Short form 36 (SF-36) was used to determine the quality of life and Multidimensional Perceived Socia Support Scale (MSPSS) was used to determine the percieved social support. The effect of three factors in MSPSS (family, friends, significant others) on quality of life of rheumatoid arthritis and fibromyalgia patients were examined seperately Results: Fibromyalgia patients had lower scores than the rheumatoid arthritis patients and healthy controls regarding the physical function, pain, social functioning and mental health subscales of SF-36 $(p<0.05)$. Regarding the all MSPSS scores, there was no significant difference between the three groups $(p>0.05)$ In rheumatoid arthritis patients, MSPSS-friend and MSPSS-significant others scores were positively correlated with all subscales of SF-36. MSPSS-family score was only correlated with pain, social functioning and mental health subscales of SF-36. But in fibromyalgia patients none of the three MSPSS scores had significant correlation with SF-36 subscales (Table-1).

Conclusion: Perceived social support especially from friends and significant others, has an important positive effect on the quality of life of rheumatoid arthritis patients. For fibromyalgia patients the effect of perceived social support on quality of life is lower than that is seen in rheumatoid arthritis.

References:

[1] De Maria M, Vellone E, Durante A, Biagioli V, Matarese M. Psychometric evaluation of the Multidimensional Scale of Perceived Social Support (MSPSS) in people with chronic diseases. Ann Ist Super Sanita 2018; 54(4):308-315.

Table 1. The effect of perceived social support on quality of life in fibromyalgia and rheumatoid arthritis patients (FMS: Fibromyalgia, RA: Rheumatoid arthritis, ${ }^{*} \mathrm{p}<0.05^{* *} \mathrm{p}<0.01$ )

\begin{tabular}{lcccccc}
\hline & & $\begin{array}{c}\text { SF-36 } \\
\text { Physical functioning }\end{array}$ & $\begin{array}{c}\text { SF-36 } \\
\text { Pain }\end{array}$ & $\begin{array}{c}\text { SF-36 } \\
\text { General health }\end{array}$ & $\begin{array}{c}\text { SF-36 } \\
\text { Social functioning }\end{array}$ & $\begin{array}{c}\text { SF-36 } \\
\text { Mental } \\
\text { health }\end{array}$ \\
\hline FMS-MSPSS & $\mathrm{r}$ & -0.034 & 0.015 & -0.187 & -0.121 & -0.115 \\
Family & $\mathrm{p}$ & 0.816 & 0.915 & 0.194 & 0.401 & 0.428 \\
FMS-MSPSS & $\mathrm{r}$ & 0.154 & 0.192 & 0.221 & 0.182 & 0.089 \\
Friend & $\mathrm{p}$ & 0.285 & 0.181 & 0.123 & 0.206 & 0.539 \\
FMS-MSPSS & $\mathrm{r}$ & 0.163 & 0.248 & 0.119 & 0.175 & -0.004 \\
Significant others & $\mathrm{p}$ & 0.258 & 0.082 & 0.412 & 0.225 & 0.976 \\
RA-MSPSS & $\mathrm{r}$ & 0,181 & 0,290 & 0,225 & 0,448 & 0,340 \\
Family & $\mathrm{p}$ & 0,173 & $0,027^{*}$ & 0,089 & $0,001^{* *}$ & $0,009^{* *}$ \\
RA-MSPSS & $\mathrm{r}$ & 0,357 & 0,352 & 0,333 & 0,376 & 0,389 \\
Friend & $\mathrm{p}$ & $0,006^{*}$ & $0,007^{* *}$ & $0,011^{*}$ & $0,004^{* *}$ & $0,003^{* *}$ \\
RA-MSPSS & $\mathrm{r}$ & 0,310 & 0,310 & 0,329 & 0,315 & 0,463 \\
Significant others & $\mathrm{p}$ & $0,018^{*}$ & $0,018^{\star *}$ & $0,012^{*}$ & $0,016^{*}$ & $0,001^{*}$ \\
RA-MSPSS & $\mathrm{r}$ & 0,334 & 0,366 & 0,350 & 0,432 & 0,487 \\
Total & $\mathrm{p}$ & $0,010^{*}$ & $0,005^{* *}$ & $0,007^{* *}$ & $0,001^{* *}$ & $0,001^{* *}$ \\
FMS-MSPSS & $\mathrm{r}$ & 0.144 & 0.251 & 0.093 & 0.153 & 0.024 \\
Total & $\mathrm{p}$ & 0.320 & 0.279 & 0.519 & 0.290 & 0.867 \\
\hline
\end{tabular}

Disclosure of Interests: None declared

DOI: 10.1136/annrheumdis-2020-eular.5673

\section{FRI0617-HPR GRADED MOTOR IMAGERY IN POSTTRAUMATIC STIFFNESS OF THE ELBOW: A PILOT STUDY}

T. Birinci ${ }^{1}$, E. Kaya Mutlu ${ }^{2}$, S. Altun ${ }^{3} .{ }^{1}$ Istanbul Medeniyet University, Department of Physiotherapy and Rehabilitation, Istanbul, Turkey; ${ }^{2}$ Istanbul UniversityCerrahpasa, Department of Physiotherapy and Rehabilitation, Istanbul, Turkey; ${ }^{3}$ Bakirkoy Dr. Sadi Konuk Training and Research Hospital, Clinics of Orthopedics and Traumatology, Istanbul, Turkey

Background: Elbow fracture is treated either conservatively or surgically followed by a period of immobilization with casting or splinting. A splint used to immobilize 